\title{
SITC.N
}

\section{MODERN HUMAN RESOURCE MANAGEMENT - AN EXAMPLE OF HOTEL "ZIRA"}

\author{
Jelena Petrović ${ }^{1 *}$, Pero Petrović ${ }^{2}$ \\ ${ }^{1}$ Hotel Courtyard by Marriott, Belgrade, Vasina 3, Belgrade, Serbia \\ ${ }^{2}$ Research professor, Institute for International Politics and Economy, Makedonska 25, Belgrade, Serbia
}

\section{Abstract:}

The world is rapidly changing in a number of different areas, including the economy, politics, technology and social aspects. All this exerts a strong impact on the way in which managers organize their work. Traditionally, they focused on delivering efficiency through large bureaucracies which are hierarchical in nature, very much around the process and stability. Such approach probably mitigates innovation and flexibility. A demand is no longer predictable and service has to be equally flexible for demand that exists nowadays. The emergence of post bureaucratic organizations is about being leaner, flatter and much more network-based. Within that network, employees are being empowered to take responsibility for producing innovations themselves. In order to speed up the process, it is essential to systematize the process of back office management. Human Resource Management strategies are being transformed by internal social networks and social human resource technologies in order to stimulate collaboration, transition into social enterprises, and change the positioning of human resource departments from back office to front office activities. All of these subjects are examined and the case study of human resource department of hotel Zira is explained and presented in detail within a specific questionnaire. One of the main challenges that the human resource management also faces is talent management and the principal responsibility of leadership is to efficiently manage talent, attract and utilize potential candidates, and eventually retain them.
\end{abstract}

\section{Key words:}

human resources,

hotel Zira,

management,

strategies,

leadership.

\section{INTRODUCTION}

The principal purpose and objective of this paper is to highlight the importance of a well-organized human resource department, such as the one in hotel Zira and to demonstrate how information technologies can help a hotel to gain the competitive advantage by taking care of its employees and demonstrating that to the most valued guests. For today's hotels, the use of new and modern technologies, such as human capital management software and its features, is extremely important. This is a way to produce the best quality service and maintain and recruit the best workforce. The examples were given regarding the ways in which modern technologies are supporting human resource processes and contributing to their improvement.

A strategic role of human resources is also highlighted not only as being important for the department itself, but also for the overall business. A subject of this research is the analysis of hotel Zira's human resource department, its main business stages, and the process of recruitment, selection and management of human resources. Also, the paper examines the training methods and steps that should be implemented to improve the optimization of work and make the workforce a strategic tool for positioning successful the hotel in the competitive market. All of that can be possible with the use of modern technologies and their devaluation and development, as the essential part of our everyday lives. This is particularly relevant when it comes to business processes in companies such as hotels in tourism and hospitality industry that are growing rapidly. The subject of this research is to show how those modern technologies enable us to organize activities related to human resource management and their workflow. Furthermore, human resource department has become an important part of any company, especially in the hotel industry where people, i.e. employees, are considered the most important segment for designing and providing successful services.

\section{HUMAN RESOURCE PLANNING AND SELECTION IN HOTEL ZIRA}

Human resource planning in hotel Zira represents a very complex job. Currently, there are around 96 employees in this hotel. In the period of increased work flow, the hotel would hire additional workforce, so that the number of temporarily employed people increased up to 10 people 
in certain periods. Those employees were usually studentsinterns, temporarily unemployed or young people that did not have much experience. They signed contracts for a limited period of time, most often via some youth society. In this way, employee fluctuation rate was $10 \%$ in the last year, while the leaving organization rate was about 5\%, mostly because employees found some other job or failed to meet management expectations. The number of those who improved was lower, while the available vacancies were filled in with those with some work experience.Due to its efficient marketing activities, hotel Zira has succeeded in differentiating itself and contributing to the tourist offer of Belgrade as well as Serbia, not only as a hotel intendedfor business people, but also for those that come for different reasons. After marketing activities, successful business of the hotel also relies on the use of information technologies (Micros Fidelio program) and reservation online systems.

Compared to other hotels in Belgrade belonging to the same category, hotel Zira stands out according to the guests reviews, comments andimpressions (Internal documentation, "Hotel Zira Belgrade").

\section{TYPES OF TRAINING AND ORIENTATION PROCESS IN HOTEL ZIRA}

The management of Hotel Zira has from its very beginnings invested in employee training within all departments-reservations, reception, sales department, restaurant department and restaurant itself. That is all necessary because this hotel is one of the first that started using modern software package for hotel and restaurant business - Micros Fidelio. Therefore, the training for work in Suite of Fidelio and Micros system that lasted for two weeks, four hours per day was necessary before the opening of the hotel so that employees could be empowered for everyday work. For the employees that later started with work and are starting now in this hotel, in case they don't have any previous experience with these programs, directors of the department are teaching and introducing them with these systems. In the first year of hotel business, there were short training sessions for employees in reception so that all of them could apply the same procedures in answering the phone, guest check-in and check-out, reservation taking etc.

Trial period lasts for three months. In case the management expectations are achieved, six month contract is signed and after a year, employee is taking the permanent job position. The principal responsibility of direct manager is to provide maximum help to every new employee so that he or she could assimilate into the working environment and connect with colleagues in order to achieve the quickest and effective duty performance. The effectiveness and efficiency of the new employee job realization depend on the success of socialization and orientation processes (Internal documentation, "Hotel Zira Belgrade").

\section{HUMAN RESOURCE MANAGEMENT TRANSFORMATION}

If the best practice of the company doesn't work, what is needed is the best system, and if one practice is pulled out of that system without managing it in whole, the practice may not be implemented well. The same is with the HR (human resource) transformation. It is important to know the roadmap of what a good HR transformation looks like. It could be divided into four phases (Ulrich, 2009):

1. The purpose of transformation (why?)

HR transformation is done to better respond to a business context. The context has general, environmental conditions (political, social, economic, demographic, and global) that change the world we live in. The context also has specific stakeholders - investors, customers, union groups, suppliers, regulators. These stakeholders and the general conditions give the reasons for performing HR transformation.

2. The result of transformation (so what?)

Question "so what?" begins to define the outcomes, and the benefits of transformation. The benefits are the capabilities that a company needs to compete and win and by capabilities it is meant - what the company is good at doing. Whatever the organization needs to be good at or known for becomes the outcome of HR transformation.

3. The way transformation is done (how?)

There are three parts and three ways of how it is done. Firstly, it is related to the way in which HR department could be changed. HR department needs a structure and a strategy so that it can respond to the expectations. HR also implies the set of HR practices - the hired people, the existing performance management systems, the communication systems and the structured organization. When doing the transformation, the accent is on the well-organized and focused on right things department, that the practices are aligned, integrated and innovated and that the people have competences for the future.

4. Providers of transformation (who?)

What is the distribution of responsibilities between the line managers or often the owners, HR professionals and employees (the recipients)?

When all of these phases come together, the successful $\mathrm{HR}$ transformation begins to effectuate in the company.

\section{SOCIAL NETWORKING AND HUMAN RESOURCES}

In modern business, social interaction and collaboration have transformed from face-to-face culture, to a virtual culture. Through simple engaging tools, employees can harness the collective intelligence of workforce and seek ideas from network, as they communicate and work together. Sharing content and knowledge in real time has never been easier because it is now possible to use different solutions to collaborate globally, anytime, anywhere and with any device. The thing that attracts researchers and the area of growing popularity is the use of social media by businesses. A report from 2012 predicted that there were approximately 1.43 billion social media users, which is an increase of $19.2 \%$ compared to 2011. Businesses are clearly concerned with this massive usage of social media, since there is still lack of knowledge and perception about the usage of social media, especially in context of service innovations. However, some of the businesses such as Facebook, Twitter or You Tube, are being represented on social media, and they see 
the usage of it as an improvement of communication with their customers through receiving valuable feedback on improving business performance $(\mathrm{Ng}, 2014)$. Some survey results proved literature confirming that employers should acknowledge social networks as an applicable recruitment tool, particularly between Generation Y and more known as the "Millennials". While all participants commonly preferred electronic methods of job application and recruitment, results indicated that Generation Y respondents use social networking websites more often than non-Generation Y respondents. Generation Y is mostly known for their technological savvy $(\mathrm{Ng}, 2014)$. According to the research encompassing 575 students from 76 schools, 59\% of generation Y students answered that they use social networking and the Internet on a daily basis. Most of them (85\%) used Facebook in the last month and $99 \%$ is looking for a job through the Internet and about $85 \%$ of them use the Internet for communication on a daily basis (Brown, 2009). The focus should be on "so what?" question, how to identify the trends and put them into practice. The thing is actually about social aspect, because it is the human resources issue. Before all the trends started to take action, there was a lot of apprehension in the market and among the human resource experts, for example, blocking of sites so that employees could not get on Facebook and other social networks. However, nowadays more and more professionals and leaders can observe that people collaborate in multiple different venues to get things done and social is a way for that to happen. The internal strategies for social networking need to start mirroring the external strategies pertaining to social networking. Social can help us to unify the employee profile or talent profile through social data, it can help get work done, and there is also the possibility for managers to gain a more complete view of employee performance through social feedback (Brown, 2009).

\section{THE ANALYSIS OF HOTEL ZIRA HUMAN RESOURCE MANAGEMENT DEPARTMENT}

Hotel systems are characterized by numerous different and complex activities. Many of those activities are tak- ing place almost every day and with approximately same chronology. Exactly day to day management is dealing with the realization of everyday activities of the systems in hotel Zira. Basically, daily management represents daily work planning and daily organization of manager's work while doing the settled activities, through its thoughtful understanding and operative treatment (work engagement) and through manager's relationship with co-workers in external and internal surroundings. Qualitative daily management importantly brings stability to business processes and the efficiency of this hotel company (Internal documentation, "Hotel Zira Belgrade").

But firstly, let us review the workforce in Zira hotel from the demographic perspective:

Considering a small-medium- sized, independent hotel, a wide workforce spectrum does not apply to hotel Zira, which numbers 96 employees. Despite hospitality industry being characterized with a high turnover rate, human resource department claims differently. They've lowered their turnover rate, by keeping the best people and treating them properly. Through developing employee career, listening to their needs and requirements, and controlling the compensation and benefits, they have created a pleasant organizational culture inside the hotel, which enables employees to progress and be satisfied with their accomplishments in everyday work. As could be seen from Chart 5 , most of the employees are male, aged from 25 to 36, with 5 to 10 years of work experience, and with most of them working in room and food and beverage division. There is only one manager inside the human resource department of hotel Zira and the only one employed within it, covering all basic aspects of human resource activities, such as planning of the needed workforce, recruiting and selecting them, taking care of their time and absence, ensuring that they are paid on time and retaining and training the right people for a certain position.

A short questionnaire was designed to check and see how a manager in the medium-sized hotel, such as Zira organizes the staff, deals with potential issues and the level of work satisfaction.

\section{Demographic data of Zira employees}

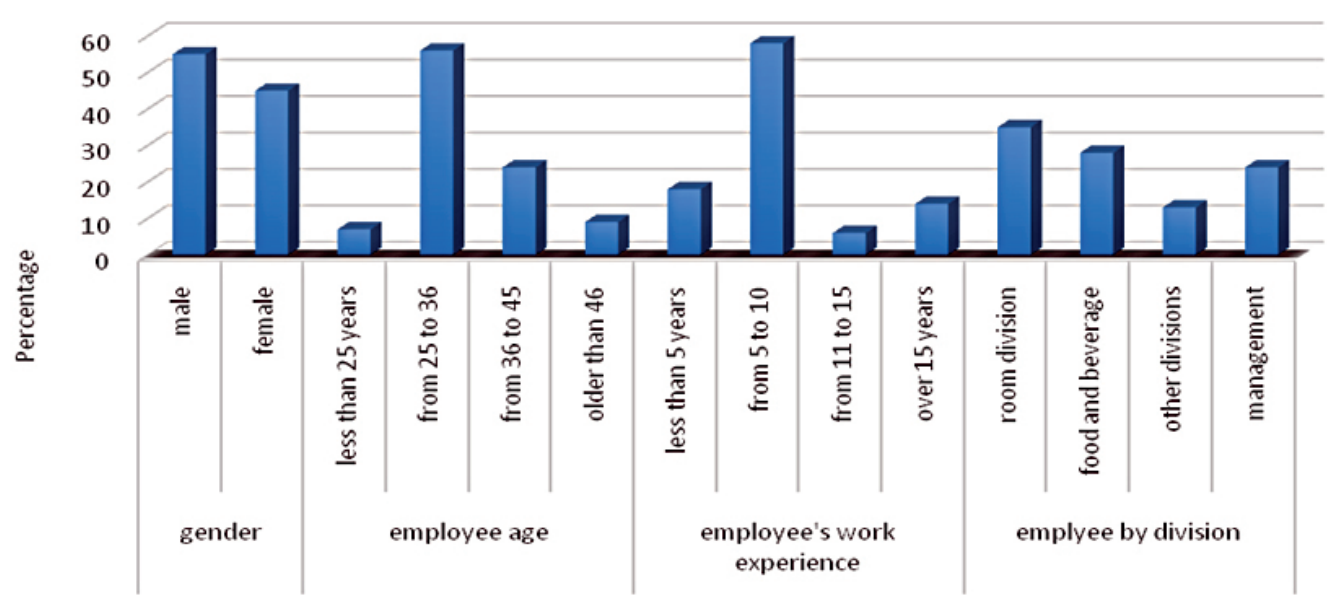

Fig 1. Demographic information about employees in hotel Zira 
1. On what level does human resource management in hotel Zira create decisions?

\section{Decision level}

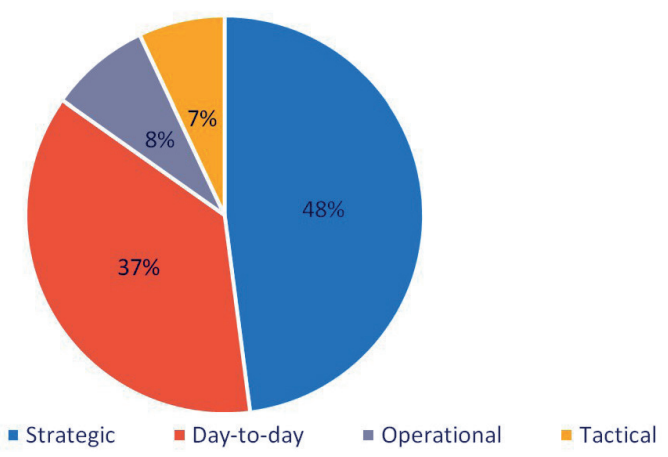

Fig 2. Decision level of human resource management

An essential part of everyday planning for a human resource manager in Zira hotel would simply have to be a notebook. It is a tool for effective working processes and an everyday reminder for completing the required tasks and obligations. Sometimes, decisions are not well-structured and have to be made instantly, and they are sometimes structured and constantly repeated. It is important that the decisions of human resource management are strategically planned.

As the human resource manager in the hotel Zira is working beside a director of a hotel in the office, his/her job tasks may involve helping the director or keeping a record on almost all the meetings, especially those concerning the budget and profit at beginning of every month.

2. How do you realize recruiting for hotel Zira?

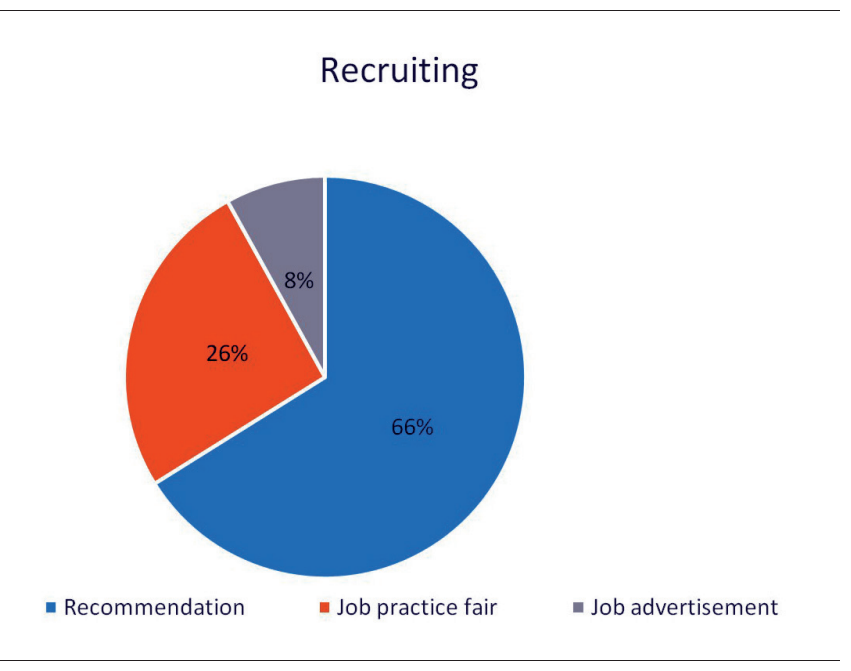

Fig 3. Realizing of recruiting in hotel Zira

As for recruitment, there are three ways of choosing the right employee for the specific job in hotel Zira:

1) Recommendation - It is the most common way of employment. It involves interviewing the people who have been sent by someone from the business community of the hotel industry in Serbia, and it is the most reliable way of recruitment considering the current situation in our country. If a trustworthy person sends a good recommendation to a human resource hotel manager, it doesn't necessarily have to mean that the person shall get the job. There are 2 or more circles that need to be passed. Firstly, there is an interview with the human resource manager and an evaluation of a potential hotel employee, and then the interview with either the head of the department or the director depending on a job position and its relevance.

2) Job practice fair - Another way of low cost selecting and recruiting a workforce. There is a 3-4 month long practice within a hotel and if the trainee showed well and there is an opening, an employment would be like a reward, plus it is simple from an orientation and training perspective since the person is already familiar with the hotel organization, people, culture and work itself.

3) Job advertisement - This is the last option for the hotel Zira human resource department in terms of recruiting, since it demands a lot of time to look at all the job applications, select the right ones and interview them.

Since hotel Zira had some bad experiences with the respondents and spent a lot of time talking with non-appropriate candidates for the job even if they didn't meet the job requirements, they are not publishing ads anymore, or only in case there is no other option.

3. How high is the level of satisfaction for you as a human resource manager and your employees?

\section{Level of work satisfaction}

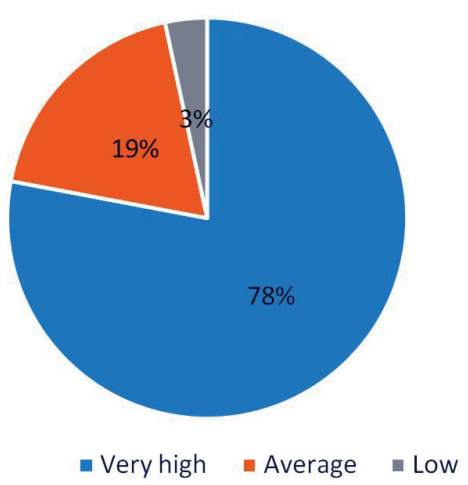

Fig 4. The level of work satisfaction of HR manager and employees

The main factor leading to a high level of work satisfaction is good communication. According to words of human resource manager in hotel Zira, employee satisfaction is based on maintaining the good and constant communication, especially if there is a problem with other employees or the tasks and instructions are not clear enough. Developing the strong connection between the manager and the main resources - employees, can bring you a competitive advantage, and boost effectiveness of everyday job activities. What particularly characterize the employees at hotel Zira are 
courtesy, professionalism and employee communication skills. Every employee carries a name tag all the time and is ready to assist guests and inform them about everything that may be relevant for them. Employees are characterized by exceptional patience; they are helpful, possess general culture and education, but also the required level of information, which is essential for business. All staff members speak English fluently, and a few of them also use another foreign language. The way in which HR department at hotel Zira sorts out and manages their employee documents is by putting them in storage, specially designed for employee data. It consists of four parts:

1) The blue coloured folder: Collects all the basic data on an employee. For example: signed job application by an employee with the picture attached, basic information about employees, their address, phone number is needed, CV, copy of an identification card, copy of a bank card, copy of a graduation diploma, certification that they've not been convicted, work book, and etc.

2) The yellow coloured folder: Agreements and annexes to the agreement and everything else that has to do with the agreements.

3) The green coloured folder: Employment and deployment documents and all the documentation related to pension, health and social assurance.

4) The red coloured one: Copy of diplomas, recommendations, punishments, sick leave verification and all other things that do not concern the other folder's content.

4. Need for automation of the business processes in human resource management for the sake of easier organization:.

\section{Need for automation}

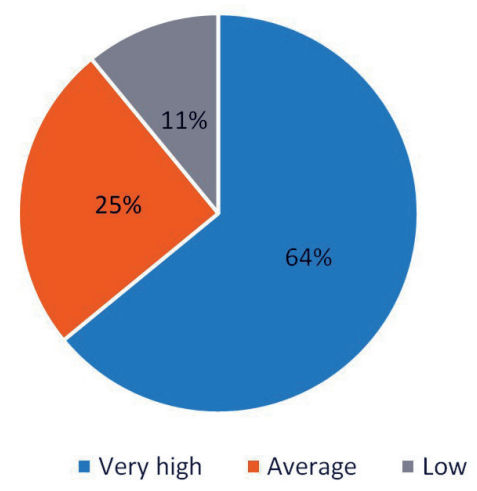

Fig 5. A need for automation of work processes in human resource department

Although HR department in hotel Zira has established a good system that is coordinating work in the simplest possible way, there are still some challenges that manager is facing. First of all, the update of important information attached to the employee file, the expiry date of the contract, required benefits, their progress, personal data, etc. According to the human resource manager, it is important to make a hotel the place where people feel comfortable, and the place where they want to be.The process of selecting the right people is critical for driving favourable business results, but human resource managers often struggle to get the right candidate. Therefore, there is a need for quality modern solutions that provide quick feedback from interviewers, have a checklist of skills to interview, and nowadays, candidates can even submit feedback on a smartphone or tablet so the manager gets it fresh and on time. The fact is that an employee faces numerous challenges, such as too much paperwork, poor communication and busy managers - all hurting time related to productivity and retention. Therefore, some kind of modern solution is required that would guide, connect and develop and help the new employees to get engaged and become productive. Laying a firm foundation for a successful career is about making a new employee feel connected and useful within the shortest possible time.

\section{CLOSING OPINION ON THE RESEARCH}

Even though human resource department in hotel Zira has been operating efficiently up to now, it is crucial to mention that business processes in contemporary world are constantly changing and since hotel industry is a robust growing business, it is important to have an efficient human resource management system with guiding technology that will lead the manager trough an employee's lifecycle. Modern human resource departments are struggling to find the technology that would help them to work faster. Therefore, another main characteristic of modern techniques would be something like social networking, as an easy way of connecting people within the company. In that way, employees could help them, ask necessary questions and get prompt response, talk to a mentor or even discover some new services and programs that company is ready to launch, arrange meetings etc. Perhaps, these are all characteristics of a large hotel chain, but some of the applications could be applied to smaller or medium-sized hotels, such as hotel Zira in Belgrade in order to achieve better work optimization of human resource department. It is probably just a matter of time when our hotels are going to implement qualitative solutions to make faster, better and accurate decisions, but also to develop human resource department.

\section{CONCLUSION}

Companies want a unified experience for their leaders and a big part of that is - mobile. Therefore, it is not about that unified experience on their lap -top, but the fact that they could be at their desk and at the same time all the data is on their tablet when they go to a meeting. In the end, everything is about the employee and about anticipating when an employee is going to make a choice about the next step in his/her career. The company should be able secure that point in time and be able to move them ahead in the organization. The thing is that if the company can predict the evolution of their high performers and if they are probably going to leave the company, to give them convenience instead and keep them longer within the organization. What all of that actually means is that the human resource management is completely transformed to fully talent pipeline, from sourcing to succession. The global view stands in the 
processes of hiring, boarding, time tracking, compensation, performance, goals, development, succession, talent reviews, payroll and the only way to do so is to have the unified experience for the people and unified experience of information for the leaders. A work is no longer an office, but rather a mindset.

\section{REFERENCES}

Zira Hotels. (2015). Prostor za konferencije. Retrieved Jun 15, 2015, from http://www.zirahotels.com/sr/meetingsand-events (In Serbian).

Čerović, S. (2013). Upravljanje ljudskim resurisma u hotelijerstvu. Beograd: Univerzitet Singidunum. (In Serbian).

Curtis, G., \& Cobham, D.P. (2004). Business information systems: Analysis, design, and practice. London: Pearson.
Hayes, D.K., \& Ninemeier, J. D. (2009). Human resources management in the hospitality industry. Hoboken, N.J: John Wiley \& Sons.

Ulrich, D. (2009). HR transformation: Building human resources from the outside in. Chicago: McGraw-Hill.

Ng, E., \& Lien, C.Y. (2014). Impact of social media in service innovations: an empirical study on the Australian hotel industry. In: Quality innovation: knowledge, theory, and practices (pp. 390-405). Hershey, PA: IGI Global.

Brown, S. (2009). Generation Y in the workplace. Texas: Bush School of Government and Public Service. Retrieved Jun 15, 2015, from http://bush.tamu.edu/research/ capstones/mpsa/projects/2009/2009GenerationYinthe Workplace.pdf

Walton, J. (1999). Strategic human resource development. Harlow: Prentice Hall. 